\section{Case Reports in Ophthalmology}

Case Rep Ophthalmol 2020;11:418-422

DOI: 10.1159/000509260

Published online: August 6, 2020
(C) 2020 The Author(s)

Published by S. Karger AG, Basel www.karger.com/cop

\title{
Rapid Regression of Scleral Melting Associated with Tumor Necrosis Factor- $\alpha$ in a Case of Surgically Induced Necrotizing Scleritis
}

\author{
Norihiko Misawa Mizuki Tagami Atsushi Sakai Takeya Kohno \\ Shigeru Honda \\ Department of Ophthalmology and Visual Sciences, Graduate School of Medicine, Osaka \\ City University, Osaka, Japan
}

\section{Keywords}

Surgically induced necrotizing scleritis $\cdot$ Tumor necrosis factor- $\alpha \cdot$ Immunohistochemistry

\begin{abstract}
Purpose: To report a case with rapid regression of scleral melting associated with tumor necrosis factor- $\alpha$ (TNF- $\alpha$ ) in a surgically induced necrotizing scleritis (SINS) patient treated with local steroid therapy. Case Presentation: An 85-year-old male patient presented with conjunctival tumor in his right eye. Complete resection of the tumor lesion and conjunctival reconstruction were performed. Local steroid drops were administered until 1 month after surgery, and a good clinical course was achieved. However, after stopping the local steroid, scleral melting to the uvea occurred on the center of the tumor-resected sclera. After diagnosing SINS, we immediately restarted his local steroid. After 2 weeks, there was a complete and rapid regression of the scleral melting. Following this episode, only local steroid therapy was continued for the treatment of SINS, with no recurrence observed after 6 months. Histopathological analysis revealed the infiltration of inflammatory cells during the acute phase, with TNF- $\alpha$ immune reactivity observed in the center of the melting site near the resected conjunctiva. Conclusion: We speculate that the observed changes were associated with the TNF- $\alpha$ that was present during the pathological state of SINS. Local steroid therapy may play a key role in the local immune balance in SINS.




\section{Case Reports in Ophthalmology}

\section{Introduction}

Surgically induced necrotizing scleritis (SINS), which is a local autoimmune response that occurs near previous surgical wounds, has been reported after various types of ocular surgery [1]. Here, we report finding SINS after primary conjunctival squamous cell carcinoma excision by conjunctival autograft. There have been no previous reports in the medical literature of SINS occurring after conjunctival tumor surgery. In addition, we also tried to elucidate the molecular biological condition of SINS.

\section{Case Report}

An 85-year-old male patient with conjunctival tumor in his right eye (uncertain onset) was referred to our department for a detailed examination. Initial evaluation showed bestcorrected visual acuity was 30/60 in his right eye, with an intraocular pressure that was within the normal range. He has been receiving anti-VEGF treatment for age-related macular degeneration over the past 5 years. For the tumor, he underwent conjunctival tumor resection and amnion transplantation without mitomycin $\mathrm{C}$ in his right eye. The patient was then started on a topical treatment that consisted of $0.5 \%$ levofloxacin and $0.1 \%$ betamethasone four times daily. The postoperative course had been good until a scleral ulcer emerged at a nasal ischemic necrotizing lesion 4 months later ( 2 months after stopping the local steroid drop treatment). The postoperative examination at 4 months showed that scleral melting to the uvea had occurred on the center of the tumor-resected sclera. The conjunctival graft was avascular with the presence of ocular pain (Fig. 1). Anterior slit-lamp examination revealed that there were no remarkable findings in the eye. Magnetic resonance imaging showed that there was no orbital lesion. After diagnosing SINS, $0.1 \%$ betamethasone was immediately restarted four times daily, preparing for an urgent scleral patch transplant surgery. The peripheral conjunctiva contact with the melting site was removed, and free conjunctival autograft transplantation was also performed. Histopathological analysis of the removed conjunctiva led to the current diagnosis and subsequent pathological search. After 2 weeks, there was complete and rapid regression of the scleral melting (Fig. 1). Following this episode, only local steroid therapy was continued for treating the SINS, and at 6 months, there has been no recurrence. However, ultrasound biomicroscopy revealed local thinning of the uvea (Fig. 1). Histopathological and immunohistochemical analysis additionally revealed infiltration of inflammatory cells during the acute phase, and TNF- $\alpha$ immune reactivity in the central part of the melting site near the resected conjunctiva (Fig. 2).

\section{Discussion}

When scleral inflammation and necrotic changes are attributed to ocular surgery, these are normally associated with autoimmunity, i.e., SINS [2,3]. The suspected mechanism of SINS might be associated with a delayed allergic response to tissue-related antigen caused by the ocular surgery [4].

In contrast, the levels of TNF- $\alpha$ and MMP-9 were increased in the tear fluid of patients compared to that of the control volunteers. The levels returned to control levels after the end of the treatment. As the diseased sclera showed an increased expression of MMP-9 compared to that for the normal donor sclera, the presence of TNF- $\alpha$ and MMP-9 may suggest that 


\section{Case Reports in Ophthalmology}

Misawa et al.: Surgically Induced Necrotizing Scleritis and Tumor Necrosis Factor- $\alpha$

disease activity of SINS could be present [5]. This appeared to be especially true in the present case, as the patient had a malignant tumor of his eye. With regard to the natural immune response, we speculated that the release of TNF- $\alpha$ was promoted by the immune-reactive cells associated with the conjunctiva and connecting tissue around the tumor [6]. In another previous report, Scheff et al. [7] stated that TNF- $\alpha$ was a prominent mediator in squamous cell carcinoma in oral cancer-induced nociception and inflammation, which highlights the need for further investigation into neural-immune communication in cancer pain. Thus, these results suggest the possibility of an association with TNF- $\alpha$.

It is possible that the use of local steroid therapy might have led to the rapid downregulation product of TNF- $\alpha$ produced by the cells located around the lesion and which once existed as part of the malignant tumor. For this reason, the restarting of the $0.1 \%$ betamethasone four times daily for only 2 weeks could have led to the complete rapid regression of the scleral melting and the remission of the ocular pain (Fig. 3). However, the problem with this hypothesis is that the half-life of TNF- $\alpha$ is very short [8]. Therefore, the other possibility is that there was only minimal survival of the original cancer cells.

\section{Conclusion}

This is the first report of a study that used immunohistochemistry methods to elucidate the association of TNF- $\alpha$ with SINS. As TNF- $\alpha$ can cause scleral thinning due to necrotizing scleritis, this is an important risk factor that requires careful follow-up in these patients. Furthermore, in these types of cases, local immunosuppression therapy and resection of the area with the upregulated TNF- $\alpha$ are an important treatment option. We speculate that TNF- $\alpha$ was associated with the pathological state of SINS.

\section{Statement of Ethics}

Although written consent to publish this case was not obtained, the patient did provide verbal informed consent. This report does not contain any personal identifying information.

\section{Disclosure Statement}

The authors have no financial disclosures or conflicts of interest to report.

\section{Author Contributions}

N.M., A.S., and M.T. cared for, worked up, treated, and collected data from the patient. T.K. and S.H. analyzed the ophthalmological findings and gave critical suggestions. M.T. performed the operation and prepared the manuscript. All authors agree to be accountable for all aspects of work. All authors attest that they meet the current ICMJE criteria for authorship. 


\section{Case Reports in Ophthalmology}

\begin{tabular}{l|l}
\hline DOI: $10.1159 / 000509260$ & (c) 2020 The Author(s). Published by S. Karger AG, Basel
\end{tabular}
www.karger.com/cop

Misawa et al.: Surgically Induced Necrotizing Scleritis and Tumor Necrosis Factor- $\alpha$

\section{References}

1 Sainz de la Maza M, Foster CS. Necrotizing scleritis after ocular surgery. A clinicopathologic study. Ophthalmology. 1991 Nov;98(11):1720-6.

2 Yamazoe K, Shimazaki-Den S, Otaka I, Hotta K, Shimazaki J. Surgically induced necrotizing scleritis after primary pterygium surgery with conjunctival autograft. Clin Ophthalmol. 2011;5:1609-11.

3 O’Donoghue E, Lightman S, Tuft S, Watson P. Surgically induced necrotising sclerokeratitis (SINS) precipitating factors and response to treatment. Br J Ophthalmol. 1992 Jan;76(1):17-21.

4 Sridhar MS, Bansal AK, Rao GN. Surgically induced necrotizing scleritis after pterygium excision and conjunctival autograft. Cornea. 2002 Apr;21(3):305-7.

5 Seo KY, Lee HK, Kim EK, Lee JH. Expression of tumor necrosis factor alpha and matrix metalloproteinase-9 in surgically induced necrotizing scleritis. Ophthalmic Res. 2006;38(2):66-70.

6 Coussens LM, Werb Z. Inflammation and cancer. Nature. 2002 Dec;420(6917):860-7.

7 Scheff NN, Ye Y, Bhattacharya A, MacRae J, Hickman DN, Sharma AK, et al. Tumor necrosis factor alpha secreted from oral squamous cell carcinoma contributes to cancer pain and associated inflammation. Pain. 2017 Dec;158(12):2396-409.

8 Aggarwal BB, Gupta SC, Kim JH. Historical perspectives on tumor necrosis factor and its superfamily: 25 years later, a golden journey. Blood. 2012 Jan;119(3):651-65.
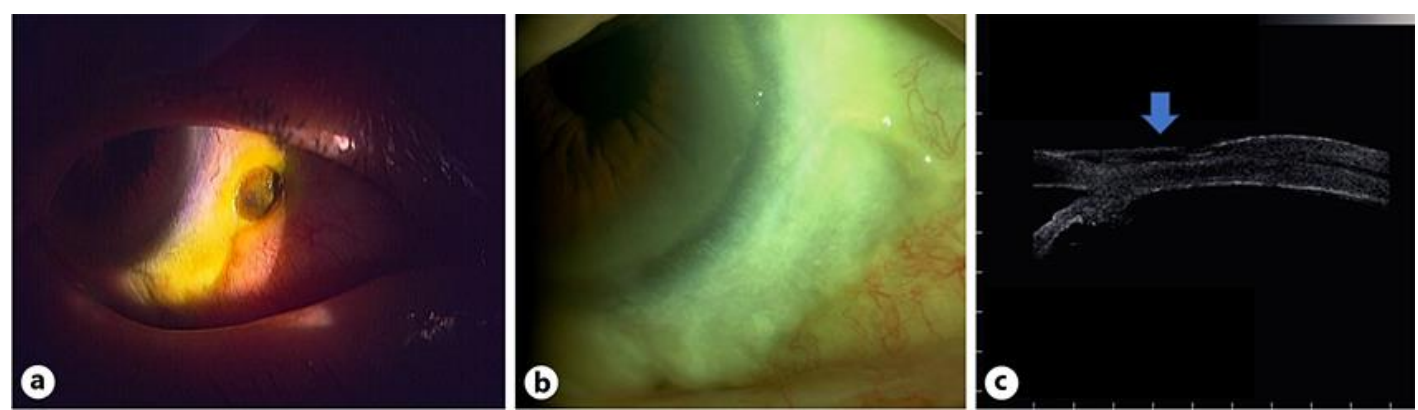

Fig. 1. Ophthalmological findings before and after treatment of a patient with SINS. a Slit-lamp photograph of the right eye showing that the presence of scleral melting to the uvea on the center of the tumor-resected sclera and the conjunctival graft was avascular. b After 2 weeks, there was complete rapid regression of the scleral melting. $\mathrm{c}$ Ultrasound biomicroscopy revealed local thinning of the uvea. 

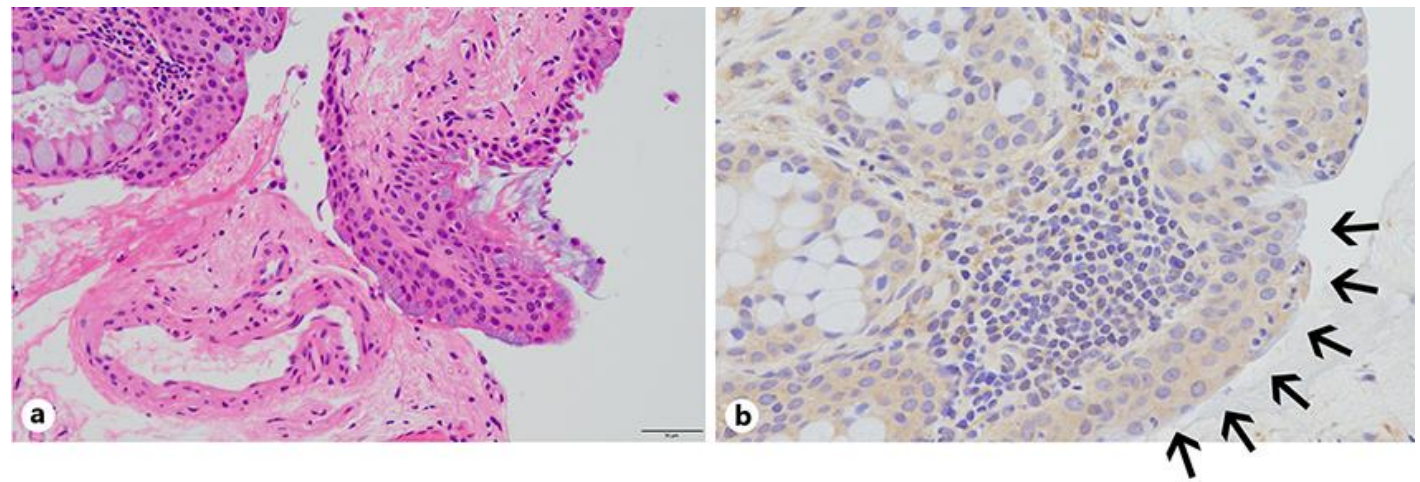

Fig. 2. Histology (a) and immunohistochemistry (b) of the resected peripheral conjunctiva. a Light micrograph demonstrating infiltration of the inflammatory cells during the acute phase (hematoxylin and eosin, bar $=50 \mu \mathrm{m}$ ). b Immunohistochemistry for TNF- $\alpha$ (anti-human TNF $\alpha$ rabbit polyclonal antibody: abcam \#ab66579) was strongly expressed in the resected conjunctiva, which was attached to center of the melting site.

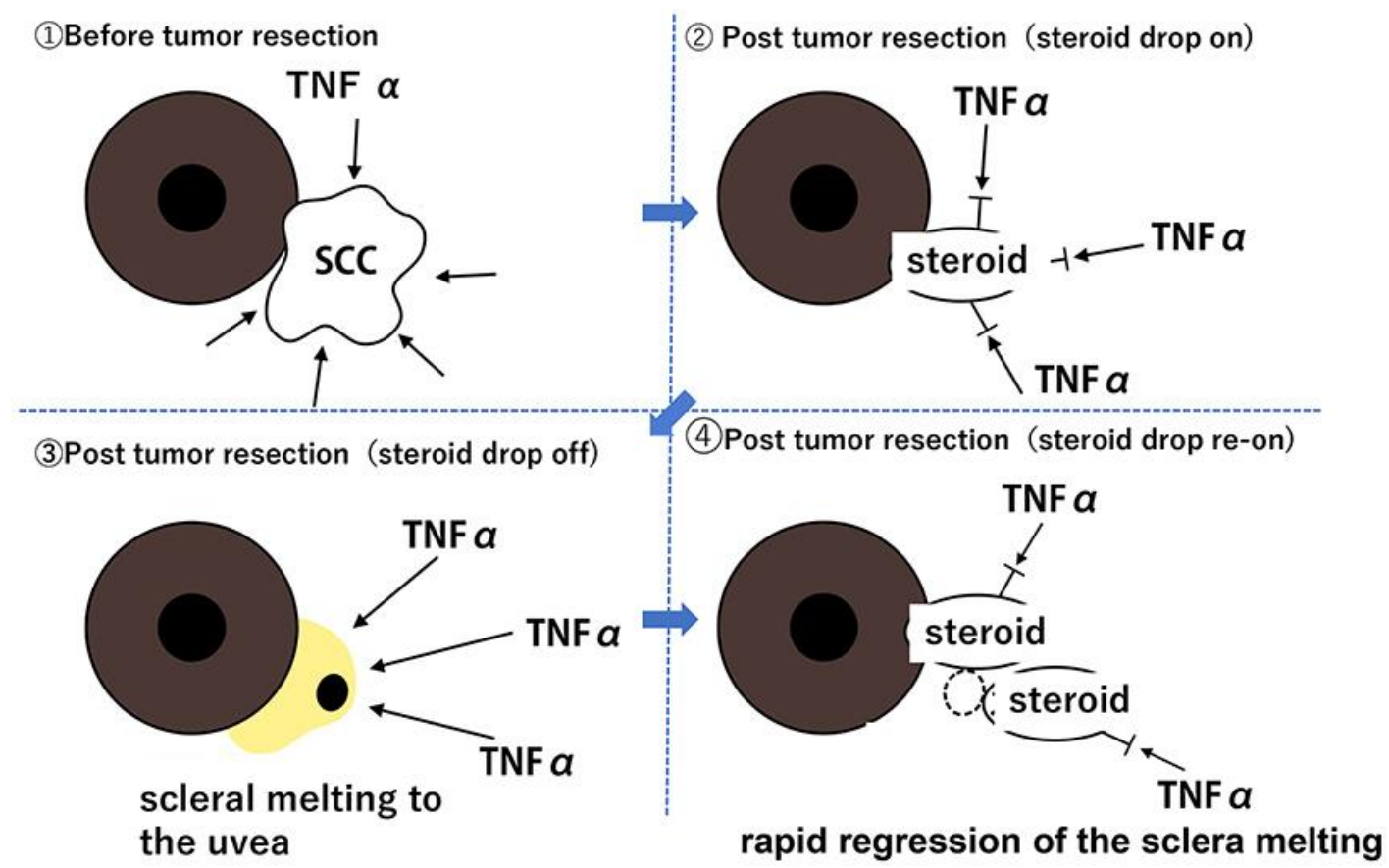

Fig. 3. Schema of our hypothesis. 